Archives de sciences sociales des religions

112 | octobre-décembre 2000

Âme et corps : conceptions de la personne

\title{
MARAVAL (Pierre), Le Christianisme de Constantin à la conquête arabe
}

Paris, P.U.F., 1997, 460 p. (bibliogr., cartes) (coll. « Nouvelle Clio »)

Michel Sot

\section{OpenEdition}

\section{Journals}

Édition électronique

URL : http://journals.openedition.org/assr/20324

DOI : $10.4000 /$ assr.20324

ISSN : $1777-5825$

\section{Éditeur}

Éditions de l'EHESS

Édition imprimée

Date de publication : 31 décembre 2000

Pagination : 104-106

ISBN : 2-222-96698-1

ISSN : 0335-5985

\section{Référence électronique}

Michel Sot, "MARAVAL (Pierre), Le Christianisme de Constantin à la conquête arabe », Archives de sciences sociales des religions [En ligne], 112 | octobre-décembre 2000, document 112.32, mis en ligne le 19 août 2009, consulté le 21 septembre 2020. URL : http://journals.openedition.org/assr/20324 ;

DOI : https://doi.org/10.4000/assr.20324

Ce document a été généré automatiquement le 21 septembre 2020

(C) Archives de sciences sociales des religions 


\section{MARAVAL (Pierre), Le Christianisme de Constantin à la conquête arabe}

Paris, P.U.F., 1997, 460 p. (bibliogr., cartes) (coll. « Nouvelle Clio »)

Michel Sot

\section{RÉFÉRENCE}

MARAVAL (Pierre), Le Christianisme de Constantin à la conquête arabe, Paris, P.U.F., 1997, 460 p. (bibliogr., cartes) (coll. « Nouvelle Clio »)

1 Traiter de l'histoire du christianisme entre le début du IV ${ }^{\mathrm{e}}$ siècle et le milieu du VII siècle, c'est aborder les questions essentielles de son implantation dans un empire romain très étendu, de la mise en place de ses institutions, diverses selon les lieux, et de la fixation durable de sa doctrine à l'issue de grandes crises presque toutes nées en Orient. P.M. donne un ouvrage de référence, informé, précis et didactique à souhait pour qui veut entrer dans la connaissance des fondements du christianisme, quelle que soit la période sur laquelle il travaille. On est frappé, à la lecture de ce livre, de voir combien l'histoire postérieure du christianisme est restée dépendante de ces siècles de genèse, en Orient comme en Occident. Un des nombreux mérites de cet ouvrage, pour l'historien du christianisme occidental, est de bien rappeler tout ce que le christianisme, même occidental, doit à l'Orient.

2 Comme le veut la collection, l'ouvrage commence par un inventaire de sources (qui privilégie celles pour lesquelles on dispose d'une traduction française) et une bibliographie de plus de 1100 titres dans les langues les plus courantes, soigneusement classée selon les parties et les chapitres du livre et hiérarchisée entre ouvrages généraux et ouvrages spécialisés. Les sources qui sont inventoriées ici et soigneusement présentées au long du livre sont celles de l'histoire des premiers siècles du christianisme mais, pour beaucoup d'entre elles, celles aussi qui serviront ensuite constamment de référence à toutes les époques de l'histoire du christianisme. 
3 La matière est répartie en trois grandes parties : l'expansion du christianisme; le développement des institutions; le développement de la doctrine. On suit aisément dans la première partie la chronologie de l'installation du christianisme de Constantin à Héraclius, les méthodes de lutte contre le paganisme et d'affirmation du christianisme avant que deux chapitres dressent un bilan de l'expansion du christianisme en Orient (y compris au-delà de l'empire romain) et en Occident, pays par pays. La seconde partie fait passer le lecteur des institutions de l'Église locale (les hommes et les choses) à celles de l'Église universelle (conciles, métropoles et grands sièges), puis aux institutions du culte où apparaissent les principales pratiques religieuses et enfin au nouveau mode de vie qui s'implante pendant cette période, avec des caractères différents en Orient et en Occident : le monachisme. La troisième partie rassemble commodément, en chapitres synthétiques, les éléments indispensables sur le développement de la doctrine. Sont examinés successivement la crise donatiste, le débat trinitaire sur les rapports entre le Père et le Fils lors de la crise arienne tranchée par le concile de Nicée (325), les débats christologiques sur l'être du Fils autour du concile de Chalcédoine (451), puis dans ses prolongements politico-religieux jusqu'au VIT siècle en Orient, sans oublier le débat sur la grâce et la liberté avec Pélage dans la première moitié $\mathrm{du} \mathrm{V}^{\mathrm{e}}$ siècle, débat qui devait être le seul a vraiment intéresser l'Occident, et jusqu'à une époque récente.

Rien de très original a priori, dans cet ouvrage, mais toute l'efficacité d'un manuel, au meilleur sens du mot. P.M. prévient d'ailleurs en introduction qu'à son livre «manque une étude approfondie de la vie concrète des chrétiens du temps, ou plutôt de la transformation que le christianisme a pu apporter concrètement à leur vie, en particulier en matière d'éthique ". Mais ce champ, pour donner lieu à synthèse, lui paraît à juste titre encore trop peu exploré. Cette affirmation est trop modeste et l'on trouve au fil des pages bien des éléments qui permettent une approche concrète de la vie des chrétiens.

5 À propos de l'expansion du christianisme, l'attention du lecteur est attirée sur le fait qu'elle s'opère d'abord et plus profondément dans la partie orientale de l'Empire romain où l'on peut la considérer comme achevée au $\mathrm{V}^{\mathrm{e}}$ siècle, alors qu'il faut attendre un peu plus tard en Occident. Cette précocité de l'Orient s'accompagne d'une grande diversité de doctrines et l'historiographie a eu tendance à privilégier la Grande Église, celle qui s'est posée comme orthodoxe, les sources concernant les autres ayant été occultées. Les empereurs chrétiens ont joué un rôle essentiel, l'universalité de l'Empire romain se confondant avec celle de l'Église, et le pouvoir impérial acquérant une durable dimension ecclésiale. L'A. insiste sur la politique des empereurs chrétiens contre le paganisme et le judaïsme, qui témoigne de la force de résistance des religions traditionnelles, païennes et juives, elles aussi trop occultées par une historiographie qui présente souvent une progression du christianisme par trop triomphale. En étudiant les méthodes de la mission chrétienne, la lutte idéologique et pratique contre les croyances et les cultes païens, mais aussi les efforts de récupération, l'A. montre bien leur vigueur. Le christianisme s'affirme d'ailleurs dans des structures qui sont celles de la culture antique : nous sommes, aux $\mathrm{IV}^{\mathrm{e}}$ et $\mathrm{V}^{\mathrm{e}}$ siècles, à la première grande époque de la littérature chrétienne, à l'âge des Pères qui ont créé la théologie chrétienne en confrontant les Écritures et la philosophie grecque. L'étude des différentes régions de l'Orient puis de l'Occident permet de voir plus précisément, dans le temps et dans l'espace, ces grands aspects, politiques et méthodiques, de l'expansion chrétienne. 
Chaque région donne lieu à une notice synthétique, indiquant les événements, la mise en place des structures chrétiennes et les crises qui l'accompagnent, les principales constructions de monuments chrétiens et les productions littéraires importantes, avec renvois à la troisième partie du livre pour les débats doctrinaux.

6 En face de cet excellent exposé, attentif à bien diriger son lecteur dans la complexité des phénomènes et la bibliographie, il faut déplorer la très mauvaise qualité des cartes, difficilement admissible chez un grand éditeur universitaire, reprises pour les unes d'un manuel vieux de 30 ans où les dénominations ne correspondent pas à celles utilisées dans le texte, dessinées pour les autres apparemment pour cet ouvrage, mais d'une extrême indigence, n'indiquant pas la moitié des noms de lieu cités dans le texte. C'est particulièrement gênant pour l'Orient, essentiel au sujet traité et moins familier au lecteur occidental.

7 L'expansion du christianisme a sans doute bénéficié de circonstances politiques favorables et de sa capacité à répondre aux aspirations des hommes des siècles considérés, mais il a bénéficié aussi d'une remarquable organisation interne, d'institutions progressivement mises en place et consolidées, qui font l'objet de la seconde partie du livre de RM.. Dès l'origine, la prédication a généré des communautés (ekklesiai $=$ Églises), dont les membres étaient les fidèles, ceux dont la foi (fides) avait été scellée par le baptême et qui avaient accès à l'assemblée eucharistique, élément central du culte chrétien. Ces communautés ont mis en place une organisation interne répartissant les rôles des membres, puis les hiérarchisant. La distinction fondamentale entre clergé et peuple (laos), clercs et laïcs, s'était mise en place dès le $\mathrm{III}^{\mathrm{e}}$ siècle : les statuts et les obligations des uns et des autres se sont ensuite fixés.

" Tout évêque est maître dans son Église » rappelle par exemple le canon 9 du concile d'Antioche en 341. Mais toutes les Églises locales n'en constituent pas moins une seule Église qui se dit elle-même catholique, c'est-à-dire « répandue dans tout l'univers ». Il y a communion entre les Églises locales, une communion qui se manifeste par la communication entre elles (des échanges de lettres) mais surtout par la réunion de synodes (mot grec) ou de conciles (mot latin). Entre les Églises une hiérarchie s'établit et les évêques de capitales de provinces ou de diocèses civils romains, voire de capitales de nouveaux États, acquièrent une prééminence sur les autres ; c'est l'origine des sièges métropolitains. Parmi ceux-ci, celui de Rome et celui de Constanti-nople entrent en concurrence, l'Église de Rome revendiquant à partir du IV siècle une primauté juridictionnelle, dépassant la primauté d'honneur que toutes les Églises lui reconnaissaient.

9 L'autonomie et la diversité des Églises se reflètent aussi dans une assez large diversité des institutions et des pratiques cultuelles. On trouvera ici d'excellents chapitres d'initiation sur la réunion eucharistique, le baptême, la pénitence, la liturgie des heures, le calendrier chrétien et les pèlerinages dont l'assimilation par les étudiants devrait éviter bien des énormités trop souvent rencontrées dans leurs travaux. De même, les origines du monachisme, traitées en deux chapitres séparés, l'un sur l'Orient et l'autre sur l'Occident, sont présentées avec une grande rigueur, en insistant sur les caractères communs comme sur les caractères originaux qu'il prend dans chacune des régions d'Orient et d'Occident envisagées séparément.

10 Reste l'essentiel, puisque l'objet du livre est le christianisme : le développement de la doctrine auquel est consacrée la troisième partie. Dans la période qui nous occupe (IV ${ }^{\text {- }}$ $\mathrm{VII}^{\mathrm{e}}$ siècle), s'est définie une orthodoxie (opinion droite) par rapport à des hérésies 
(étymologiquement des choix) qui en viennent rapidement à désigner toute doctrine opposée à l'orthodoxie. "Bien entendu, dans ces débats, chaque parti a revendiqué l'orthodoxie pour lui-même et accusé ses adversaires d'hérésie» souligne l'A. L'historien doit éviter d'utiliser ces termes de manière absolue. Ce sont donc de grands «débats» qui font l'objet des chapitres de cette troisième partie: débat sur la conception de l'Église avec la crise donatiste en Afrique ; débat sur les rapports du Père et du Fils dans la Trinité avec la crise arienne, né en Égypte, tranché en principe au premier concile de Nicée en 325, et qui eut d'importante répercussions dans l'Occident "barbare»; débat surtout sur l'être du Fils, tranché en principe au concile de Chalcédoine en 451, mais qui se poursuit en Orient jusqu'au milieu du VIP siècle ; débat enfin sur la grâce et la liberté engagé par Pélage, moine breton établi à Rome, qui touche surtout l'Occident.

L'ouvrage que propose P.M. est un ouvrage de référence par son contenu qui balaie l'ensemble des questions politiques, institutionnelles et doctrinales de trois siècles essentiels de l'histoire du christianisme. Par ses renvois constants et précis aux sources et à la bibliographie il est un instrument de recherche. Il honore la collection « Nouvelle Clio » et sa devise : « l'histoire et ses problèmes ». 